\title{
Price Pressure around Mergers and Acquisitions: Evidence from Shanghai A Shares
}

\author{
Jui-Jung Tsai, Yang-Chao Wang* \\ Newhuadu Business School \\ Minjiang University \\ Fuzhou, China
}

\author{
Yingrong Chen \\ European and Chinese Business Management \\ University of Zurich \\ Zurich, Switzerland
}

\begin{abstract}
In 2015, China's mergers and acquisitions (M\&As) were in the ascendant, accounting for $15 \%$ of global M\&A transactions and worth more than 734 billion US dollars. Over 100 individual transactions exceeded 1 billion US dollars. Meanwhile, research on $M \& A$ performance and value has become a hot topic in both empirical and theoretical fields. At present, studies on M\&As primarily focus on performance, influential factors, and integration problems. By contrast, this study begins with the perspective of the announcement effect. In this study, we find negative linkages between cumulative average abnormal returns (CAARs) and short selling amount around M\&A announcement dates. Short selling plays a pivotal role in downward price pressure for stock-financed mergers. Further, we find opposite price pressure surrounding merger closings, particularly for the constituent stocks of the Shanghai Composite Index. This may be explained by portfolio rebalancing due to tracking the stock index.
\end{abstract}

\section{Keywords-M\&A; Event study; CAAR; Short selling}

\section{INTRODUCTION}

Between the second half of 2014 and the first half of 2015 , China was undergoing a bullish stock market. The Shanghai Composite Index (SCI) increased from 2070.72 points in June 13, 2014 to 5166.35 points in June 12, 2015. Along with the booming stock market, information disclosure systems have been improving dramatically, and merger and acquisitions (M\&As) have been growing at tremendous rates. For example, there were $577 \mathrm{M} \& \mathrm{~A}$ events in 2005, among which $572 \mathrm{M} \& \mathrm{~A}$ events were successful, while there were $2502 \mathrm{M} \& \mathrm{~A}$ events in 2013, with successful 2451 deals. During 2005-2014, there were a total 18149 M\&A events, of which 17636 were successful. In 2015, China's M\&As were in the ascendant, with $15 \%$ of global M\&A transactions coming from China. The total amount increased by nearly $85 \%$ over the same period the previous year, to over 734 billion US dollars, with more than 100 individual transactions exceeding 1 billion US dollars. Therefore, M\&As have increasing influence on the stock market.

Equally noteworthy, China's stock market has reached new milestones in recent years (see Ma et al. [1]; Wang et al. [2]). Prior studies show policy implementations greatly affect China's stock market (see Guo et al. [3]; Huo and Ahmed [4]; Tsai et al. [5] and Wang et al. [6]). Among these, margin trading and short selling are one of the most important sources.

This research was financially supported by the Natural Science Foundation of Fujian Province, China (Grant No. 2017J01800 and 2016J05174), the Special Foundation of Higher Education of Fujian Province, China (Grant No. JK2015039), the Research Project for Young and MiddleAged Faculty of Fujian Province, China (Grant No. JAS160403), and the Special Foundation of Minjiang University for Taiwanese Teachers (Grant No YKZ17003 and YKZ17004).
Investors are able to buy stocks on margin and borrow stocks to sell since March 31, 2010. The number of stocks that can be shorted increased from 285 in 2011 to 901 in 2014. Accordingly, the pattern of M\&A influence on the stock market has changed greatly during the period since the short selling mechanism began in China's stock market.

Therefore, it is essential to investigate this issue because short selling of merger arbitrage usually causes negative price responses, particularly for stock-financed mergers (Shleifer and Vishny, [7]; Mitchell et al., [8]). Titman et al. [9] investigate this phenomenon and argue that when investment expenditure is high, acquiring firms may adjust the expenditure and expand capital to promote their performance. Consequently, investors could have a tendency to short the stocks without awareness of firms' real motivations because sometimes firms choose the stock-financed mergers when their stocks are overvalued. In contrast to the stock-financed mergers, when acquiring firms use cash as the payment, positive abnormal returns may result. Vafeas and Shenoy [10] argue that announcement-period returns follow in capital-spending decisions. This is consistent with the findings of Jones et al. [11]. They find that abnormal returns change based on the category of capital investment announcements. Furthermore, Akbar et al. [12] investigate the stock market's response to the information disclosure of capital expenditure by UK companies. They find strong relations between capital expenditure and abnormal returns. Therefore, M\&As, as an important form of information disclosure, have an influential effect.

Mergers and Acquisitions (M\&As) are an important method of enlarging enterprise scale and realizing enterprise expansion, and also a primary form of enterprise long-term capital expenditure. Research on M\&A performance and value has thus become a hot topic in both empirical and theoretical fields now. At present, research on M\&As mainly focuses on performance, influential factors, and integration problems, along with several other aspects (e.g. Agrawal and Jaffe, [13]; Sorensen, [14]; Bae et al., [15]; Dutta and Jog, [16]). By contrast, this study begins from the perspective of the announcement effect and takes the Shanghai stock market as the research subject. In this study, we investigate how M\&A announcements impact the stock market and how cumulative average abnormal returns evolve around M\&A events through calculation of the abnormal returns in the period before and after the initial announcement dates. 


\section{DATA ANALYSIS}

The sample period is from January 1, 2011 to December 31, 2014. The variables of our data include M\&A events, sample stocks' daily returns and circulation shares, returns of the
Shanghai Composite Index, and the stock lending shares of securities margin trading. All variables are collected from the GTA database. The sample selection process is reported in Table 1. To guarantee the effectiveness of the estimated effects, some companies are excluded.

TABLE I. SAMPLE SELECTION PROCESS

\begin{tabular}{lrrrrr}
\hline \multicolumn{1}{c}{ Condition Names } & 2011 & 2012 & 2013 & 2014 & Total \\
\hline Total M\&A and restructuring announcements & 6198 & 7543 & 10678 & 7667 & 32086 \\
(-): Non-margin trading and short selling & 3190 & 4177 & 5826 & 4449 & 17642 \\
Non-Shanghai Stock Market & 1354 & 1495 & 2306 & 1287 & 6442 \\
Non-M\&A announcements & 867 & 1228 & 1875 & 1376 & 5346 \\
Unsuccessful M\&As & 18 & 15 & 12 & 5 & 50 \\
Affiliate transaction & 410 & 366 & 363 & 275 & 1414 \\
Under 10 million yuan & 185 & 46 & 43 & 38 & 312 \\
Announcements of one company on one date & 42 & 56 & 53 & 42 & 193 \\
\hline \multicolumn{1}{c}{ Total } & 132 & 160 & 200 & 195 & 687 \\
\hline
\end{tabular}

The dates for M\&A announcements consist of initial, latest, and finishing announcement dates. The initial announcement date is the first time when firms make M\&A information public to investors. Hence, it has the greatest effect. Accordingly, we choose the initial announcement date as the event date. As Figure 1 shows, $E$ is the event date, $\left[T_{1}, T_{2}\right],\left[T_{3}, T_{4}\right]$, and $\left[T_{5}, T_{6}\right]$

are the estimation, event, and posterior periods, respectively. Further, we define the estimation, event, and posterior periods as $[-90,-31],[-30,30]$, and $[31,90]$ to estimate expected returns, calculate abnormal returns (ARs), and observe the post-event outcome.

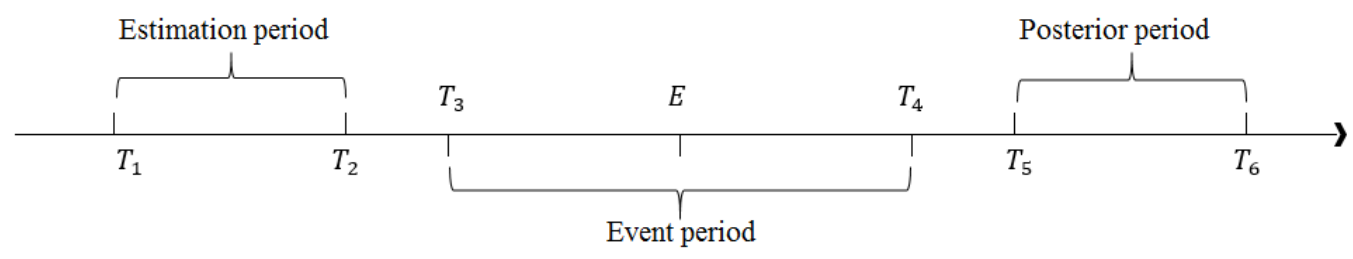

Fig. 1. Event, estimation, and posterior periods

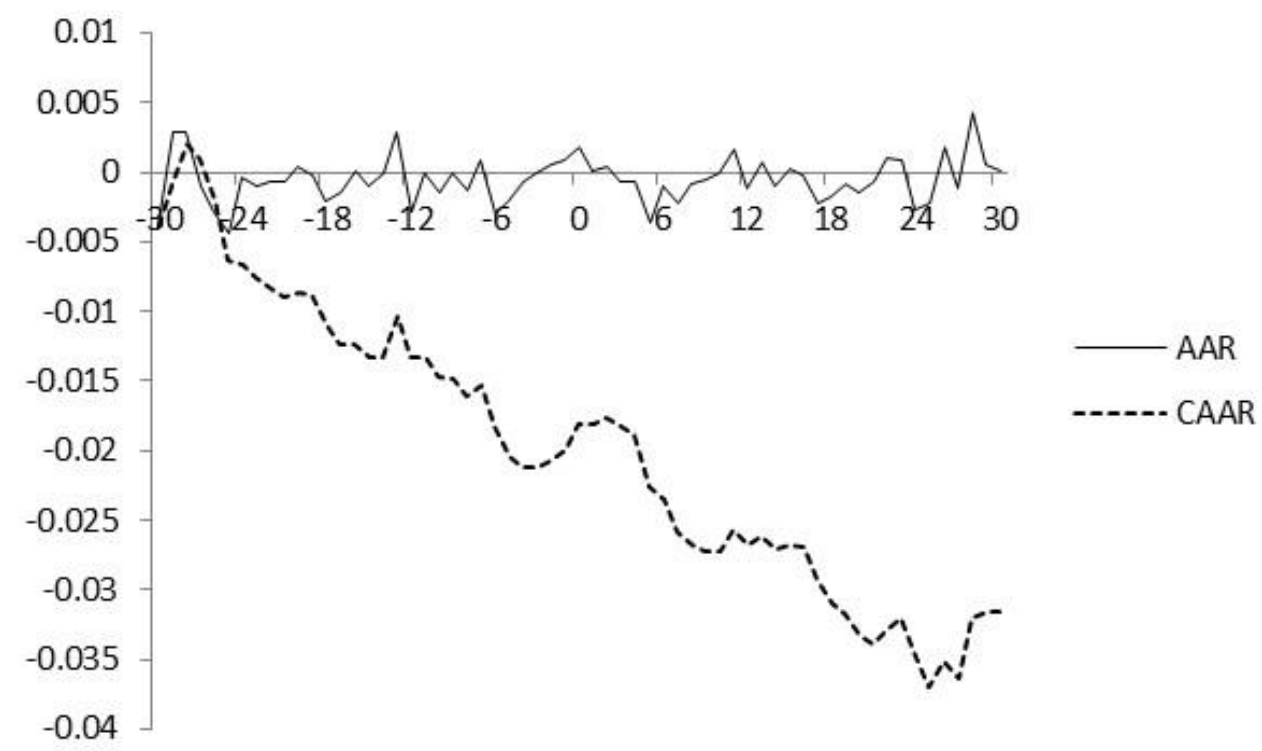

Fig. 2. Time series of AARs and CAARs 
TABLE II. AARS AND CAARS IN THE EVENT PERIOD

\begin{tabular}{|c|c|c|c|c|c|}
\hline Date & AAR & CAAR & Date & AAR & CAAR \\
\hline-30 & -0.00387 & -0.00387 & 1 & $9.05 \mathrm{E}-5$ & -0.01802 \\
\hline-29 & 0.00291 & -0.00096 & 2 & 0.00041 & -0.01761 \\
\hline-28 & 0.00292 & 0.00196 & 3 & -0.00061 & -0.01822 \\
\hline-27 & -0.00106 & 0.00090 & 4 & -0.00066 & -0.01888 \\
\hline-26 & -0.00283 & -0.00192 & 5 & -0.00367 & -0.02256 \\
\hline-25 & -0.00445 & -0.00638 & 6 & -0.00102 & -0.02358 \\
\hline-24 & -0.00032 & -0.00671 & 7 & -0.00226 & -0.02584 \\
\hline-23 & -0.00091 & -0.00763 & 8 & -0.00085 & -0.02670 \\
\hline-22 & -0.00071 & -0.00834 & 9 & -0.00057 & -0.02727 \\
\hline-21 & -0.00063 & -0.00897 & 10 & $-8.23 \mathrm{E}-6$ & -0.02728 \\
\hline-20 & 0.00034 & -0.00863 & 11 & 0.00157 & -0.02570 \\
\hline-19 & -0.00023 & -0.00887 & 12 & -0.00113 & -0.02683 \\
\hline-18 & -0.00212 & -0.01099 & 13 & 0.00076 & -0.02607 \\
\hline-17 & -0.00139 & -0.01239 & 14 & -0.00093 & -0.02700 \\
\hline-16 & $9.41 \mathrm{E}-5$ & -0.01229 & 15 & 0.00020 & -0.02680 \\
\hline-15 & -0.00097 & -0.01327 & 16 & -0.00016 & -0.02696 \\
\hline-14 & $-7.40 \mathrm{E}-5$ & -0.01334 & 17 & -0.00223 & -0.02920 \\
\hline-13 & 0.00293 & -0.01041 & 18 & -0.00170 & -0.03091 \\
\hline-12 & -0.00289 & -0.01330 & 19 & -0.00086 & -0.03178 \\
\hline-11 & $-3.84 \mathrm{E}-5$ & -0.01334 & 20 & -0.00148 & -0.03326 \\
\hline-10 & -0.00139 & -0.01473 & 21 & -0.00065 & -0.03391 \\
\hline-9 & $-6.09 E-5$ & -0.01480 & 22 & 0.00105 & -0.03285 \\
\hline-8 & -0.00132 & -0.01612 & 23 & 0.00081 & -0.03204 \\
\hline-7 & 0.00081 & -0.01530 & 24 & -0.00271 & -0.03475 \\
\hline-6 & -0.00299 & -0.01829 & 25 & -0.00218 & -0.03693 \\
\hline-5 & -0.00214 & -0.02044 & 26 & 0.00179 & -0.03514 \\
\hline-4 & -0.00069 & -0.02114 & 27 & -0.00119 & -0.03633 \\
\hline-3 & $-9.85 \mathrm{E}-5$ & -0.02124 & 28 & 0.00425 & -0.03208 \\
\hline-2 & 0.00053 & -0.02070 & 29 & 0.00055 & -0.03153 \\
\hline-1 & 0.00081 & -0.01989 & 30 & $2.73 \mathrm{E}-5$ & -0.03150 \\
\hline 0 & 0.00178 & -0.01811 & & & \\
\hline
\end{tabular}

${ }^{\text {a. }}$ Note: The AAR and CAAR denote the average abnormal return and cumulative average abnormal return, respectively.

After defining the related periods, we can use the marketadjusted return model to calculate the corresponding average abnormal returns (AARs) and cumulative average abnormal returns (CAARs) in the M\&A event period. The results for 2013 are presented in Table 2 and Figure 2. This study investigates the effects of M\&A events for each year from 2011 to 2014. To save space, we only show the results for 2013. The remaining results are available on request.

As Table 2 and Figure 2 show, the AAR and CAAR for the event date are 0.0018 and -0.0181 . It can be seen evidently from Figure 2 that AARs during the event period [-30, 30] are slightly volatile in an irregular pattern around zero between
-0.005 and 0.005 . However, the CAARs present a tendency of continuous decline before and after the event date. The CAARs of the event date and 30 trading days after the event date reach around -0.02 and -0.03 , respectively. Namely, these results show negative price pressure for acquiring firms' stocks in M\&A events. The test statistic for CAARs is significant ( $\mathrm{p}$ value is smaller than 0.01 ) with a $95 \%$ confidence interval $(-0.0224,-0.0172)$. Hence, the M\&A announcement effects are quite significant. Furthermore, the results show CAARs rebound and increase near the merger closings. The effects are more pronounced when we observe the post-event outcome in the posterior period. By cross-analysis of stocks, the effects 
appear to be particularly strong for the constituent stocks of the Shanghai Composite Index. This may be explained by portfolio rebalancing due to tracking the stock index. Moreover, the results of CAARs from 2011 to 2014 all show a similar pattern, further supporting the contention of this study that short selling and portfolio rebalancing are responsible for price pressure evolution.

\section{CONCLUSION}

This study investigates price pressure effects in the Chinese stock market by examining the AARs and CAARs around M\&A initial announcement dates and finds evidence to support the existence of price pressure. The results turn out to be compatible with findings on price pressure effects in the U.S. stock market. Along with the further reform of China's stock market, short selling is bound to be applicable to more stocks. In addition, investors are increasingly accepting of short selling. Consequently, it will be more common for investors to respond negatively to great events in the stock market, making the price pressure more pronounced. The pattern of CAARs caused by short selling and portfolio rebalancing will thus be further strengthened.

\section{REFERENCES}

[1] M. Ma, X. Sun, M. Waisman, and Y. Zhu, "State ownership and market liberalization: Evidence from China's domestic M\&A market," Journal of International Money and Finance, vol. 69, pp. 205-223, December 2016.

[2] Y.-C. Wang, J.-J. Tsai, and Q. Li, "Policy impact on the Chinese stock market: From the 1994 bailout policies to the 2015 Shanghai-Hong Kong Stock Connect," International Journal of Financial Studies, vol. 5(1), pp. 4:1-19, March 2017.

[3] F. Guo, J. Hu, and M. Jiang, "Monetary shocks and asymmetric effects in an emerging stock market: The case of China," Economic Modelling, vol. 32, pp. 532-538, May 2013.
[4] R. Huo and A.D. Ahmed, "Relationships between Chinese stock market and its index futures market: Evaluating the impact of QFII scheme," Research in International Business and Finance, In Press, 2017.

[5] J.-J. Tsai, Y.-C. Wang, and K. Weng, "The asymmetry and volatility of the Chinese stock market caused by the "New National Ten"," Emerging Markets Finance and Trade, vol. 51, pp. S86-S98, 2015.

[6] Y.-C. Wang, J.-J. Tsai, and Y. Lin, "The influence of Shanghai-Hong Kong Stock Connect on the Mainland China and Hong Kong stock markets," International Journal of Business and Finance Research, vol. 10(3), pp. 1-10, 2016.

[7] A. Shleifer and R.W. Vishny, "Stock market driven acquisitions," Journal of Financial Economics, vol. 70(3), pp. 295-311, December 2003.

[8] M. Mitchell, T. Pulvino, and E. Stafford, "Price pressure around mergers," The Journal of Finance, vol. 59(1), pp. 31-63, February 2004.

[9] S. Titman, K.C.J. Wei, and F. Xie, "Capital investments and stock returns," Journal of financial and Quantitative Analysis, vol. 39(4), pp. 677-700, December 2004.

[10] N. Vafeas and C. Shenoy, "An empirical investigation of capital expenditure announcements," Applied Economics Letters, vol. 12(14), pp. 907-911, 2005.

[11] E. Jones, J. Danbolt, and I. Hirst, "Company investment announcements and the market value of the firm," The European Journal of Finance, vol. 10(5), pp. 437-452, 2004.

[12] S. Akbar, S.Z. Ali Shah, and I. Saadi, "Stock market reaction to capital expenditure announcements by UK firms," Applied Financial Economics, vol. 18(8), pp. 617-627, 2008.

[13] A. Agrawal and J.F. Jaffe, "The post-merger performance puzzle," Advances in Mergers and Acquisitions, vol 1, pp. 7-41, 2000.

[14] D.E. Sorensen, "Characteristics of merging firms," Journal of Economics and Business, vol. 52(5), pp. 423-433, September-October 2000 .

[15] K.-H. Bae, J.-K. Kang, and J.-M. Kim, "Tunneling or value addition?Evidence from mergers by Korean business groups," Journal of Finance, vol. 57(6), pp. 2695-2740, December 2002.

[16] S. Dutta and V. Jog, "The long-term performance of acquiring firms: A re-examination of an anomaly," Journal of Banking \& Finance, vol. 33(8), pp. 1400-1412, August 2009. 